\title{
Action of antimicrobial photodynamic therapy on heterotypic biofilm: Candida albicans and Bacillus atrophaeus
}

\author{
Michelle Peneluppi Silva ${ }^{1}$ - Thais Alves dos Santos ${ }^{1}$ Patrícia Pimentel de Barros ${ }^{1}$. \\ Felipe de Camargo Ribeiro ${ }^{1}$ - Juliana Campos Junqueira ${ }^{1}$. \\ Antonio Olavo Cardoso Jorge ${ }^{1}$
}

Received: 7 June 2015 / Accepted: 14 January 2016 /Published online: 9 February 2016

(C) Springer-Verlag London 2016

\begin{abstract}
The increase in survival and resistance of microorganisms organized in biofilms demonstrates the need for new studies to develop therapies able to break this barrier, such as photodynamic therapy, which is characterized as an alternative, effective, and non-invasive treatment. The objective was to evaluate in vitro the effect of antimicrobial photodynamic therapy on heterotypic biofilms of Candida albicans and Bacillus atrophaeus using rose bengal $(12.5 \mu \mathrm{M})$ and lightemitting diode (LED) (532 nm and 16.2 J). We used standard strains of B. atrophaeus (ATCC 9372) and C. albicans (ATCC 18804). The biofilm was formed in the bottom of the plate for 48 h. For the photodynamic therapy (PDT) experimental groups, we added $100 \mu \mathrm{L}$ of rose bengal with LED $(\mathrm{P}+\mathrm{L}+)$, $100 \mu \mathrm{L}$ of rose bengal without $\mathrm{LED}(\mathrm{P}+\mathrm{L}-), 100 \mu \mathrm{L}$ of $\mathrm{NaCl}$ $0.9 \%$ solution with LED ( $\mathrm{P}-\mathrm{L}+)$, and a control group without
\end{abstract}

Michelle Peneluppi Silva

michellepeneluppi@gmail.com

Thais Alves dos Santos

alves.t@live.com

Patrícia Pimentel de Barros

barrosdnapp@yahoo.com.br

Felipe de Camargo Ribeiro

felipe_c_ribeiro@hotmail.com

Juliana Campos Junqueira

juliana@fosjc.unesp.br

Antonio Olavo Cardoso Jorge

olavojorge@fosjc.unesp.br

Department of Biosciences and Oral Diagnosis, Institute of Science and Technology, UNESP - Univ Estadual Paulista, Av. Eng.

Francisco José Longo 777, São Dimas, São José dos Campos CEP: 12245-000, SP, Brazil photosensitizer or LED $(\mathrm{P}-\mathrm{L}-)$. The plates remained in agitation for $5 \mathrm{~min}$ (pre-irradiation) and were irradiated with LED for $3 \mathrm{~min}$, and the biofilm was detached using an ultrasonic homogenizer for $30 \mathrm{~s}$. Serial dilutions were plated in BHI agar and HiChrom agar and incubated at $37^{\circ} \mathrm{C} / 48 \mathrm{~h}$. There was a reduction of 33.92 and $29.31 \%$ of colony-forming units per milliliter $(\mathrm{CFU} / \mathrm{mL})$ for $C$. albicans and B. atrophaeus, respectively, from the control group to the group subjected to PDT. However, statistically significant differences were not observed among the $\mathrm{P}+\mathrm{L}+, \mathrm{P}+\mathrm{L}-, \mathrm{P}-\mathrm{L}+$, and $\mathrm{P}-\mathrm{L}-$ groups. These results suggest that antimicrobial photodynamic therapy using rose bengal $(12.5 \mu \mathrm{M})$ with a pre-irradiation period of $5 \mathrm{~min}$ and LED for $3 \mathrm{~min}$ was not enough to cause a significant reduction in the heterotypic biofilms of C. albicans and B. atrophaeus.

Keywords Photodynamic therapy $\cdot$ Bacillus atrophaeus · Candida albicans $\cdot$ Biofilm

\section{Introduction}

Due to increasing fungal and bacterial resistance to antimicrobials, many researchers have investigated non-conventional therapies for the treatment of infections. Photodynamic therapy (PDT) involves the application of a photoactive substance called a photosensitizer and a light source with a wavelength suitable to activate the photosensitizer molecules in the presence of oxygen. After activation, it generates an excited state of the photosensitizer molecules [1]. These procedures result in a cytotoxic photodynamic reaction involving the production of reactive oxygen species and sequential oxidative reactions, leading to cell death [2].

Bacillus atrophaeus is a Gram-positive bacteria used in studies as a classical non-pathogenic surrogate of Bacillus 
anthracis [3]. It is easy to culture, has identified resistance characteristics, and is used in a variety of applications [4]. Despite being classified for many years solely as soil microorganisms, Bacillus are also commensal microorganisms in the human gut due to their great adaptability to the intestinal environment, representing a part of the natural life cycle [5].

Candida albicans is a commensal yeast and important human pathogen that presents as a major virulence factor with biofilm formation and is responsible for most cases of oral and systemic candidiasis $[6,7]$.

Biofilm formation is a survival mechanism that allows the on-site permanence of microorganisms. In the structure of the biofilm, bacteria and fungi are typically encapsulated in a matrix of glycoprotein and polysaccharide produced by microbial components, which often remain in a state of reduced metabolic activity $[8,9]$. The microbial species of the biofilm are highly interactive and use intercellular signaling systems or quorum sensing. This phenomenon promotes collective behavior in the microbial population by improving access to nutrients and niches, as well as promoting a collective defense against other competitive organisms [10].

According to Martin et al. [11], the interactions between bacteria and fungi influence their survival and proliferation and may be beneficial for the microorganisms, increasing their resistance to antimicrobials or antagonists causing the death of even one component [12], as well as interfering with the survival of the host [13].

This study evaluated, in vitro, the effect of photodynamic therapy on a heterotypic biofilm formed by the association of B. atrophaeus and C. albicans using the photosensitizer rose bengal and a green light-emitting diode (LED).

\section{Methodology}

\section{Microorganisms and growth conditions}

We used standard strains of B. atrophaeus (ATCC 9372) and C. albicans (ATCC 18804) plated on brain heart infusion agar (Difco, Detroit, USA) and Sabouraud dextrose agar (Difco, Detroit, USA), respectively. After growth, the colonies of microorganisms were suspended in phosphate-buffered saline (PBS) and centrifuged for $10 \mathrm{~min}$ at $1300 \times g$ (MPW 350, Biosystems, Curitiba, Brazil). The cell pellet was then resuspended in $1 \mathrm{~mL}$ PBS. The number of viable cells in suspension was counted using a spectrophotometer (B582, Micronal, São Paulo, Brazil), and a standard suspension of the strain was prepared in PBS at a concentration of $10^{7}$ cells $/ \mathrm{mL}$. The parameters of optical density and wavelength used were, respectively, 0.381 and $530 \mathrm{~nm}$ for C. albicans and 0.269 and $307 \mathrm{~nm}$ for B. atrophaeus.

\section{Biofilm formation}

The biofilm formation was based on the methodology described by Seneviratne et al. [14] and Bridier et al. [15] with modifications. Heterotypic biofilms were obtained by the association of C. albicans and B. atrophaeus and formed in the bottom of a 96-well microtiter plate (Costar Corning, New York, USA) by pipetting in $100 \mu \mathrm{L}$ of a standardized suspension of $10^{7}$ cells $/ \mathrm{mL}$ of each microorganism. The plate was incubated under shaking at $75 \mathrm{rpm}$ rotation (Quimis Diadema, England) for $90 \mathrm{~min}$ at $37^{\circ} \mathrm{C}$. The wells with formed biofilms were washed with PBS to remove the non-adhered cells and incubated for $24 \mathrm{~h}$. After this period, the wells were washed again, and the broths were changed. The plates were incubated for $48 \mathrm{~h}$.

\section{In vitro photosensitization}

After 48-h incubation, the wells were washed with PBS for the application of PDT. We used the photosensitizer rose bengal (Sigma, São Paulo, Brazil) at a 12.5- $\mu \mathrm{M}$ concentration and the incubation time of $5 \mathrm{~min}$. A green LED (MMOptics, São Carlos, Brazil) with a wavelength of $532 \pm 10 \mathrm{~nm}, 90 \mathrm{~mW}$ output power, and $16.2 \mathrm{~J}$ energy was used as the light source.

The experimental groups are shown in Table 1.

The plates containing the biofilm remained in preirradiation time for $5 \mathrm{~min}$ in an orbital shaker (Solab, Piracicaba, Brazil) to increase the penetration of the photosensitizer into the microorganisms. The cells were not washed after the pre-irradiation. Each experimental group was repeated 10 times (number of tests equal to 10), with a total of 40 trials for C. albicans biofilm and 40 trials for B. atrophaeus, resulting in 80 trials for the complete experiment.

After irradiation, excess photosensitizer was removed with PBS, and the wells were homogenized for $30 \mathrm{~s}$ in an ultrasonic homogenizer (Sonics Vibra Cell, Connecticut, USA) with $25 \%$ amplification to detach the biofilm. Serial dilutions of suspensions were performed, and a $100-\mu \mathrm{L}$ aliquot of each dilution was plated on brain heart infusion agar for B. atrophaeus and HiCrome Candida differential agar (Himedia, Mumbai, India) for C. albicans and incubated at $37^{\circ} \mathrm{C}$ for 24 and $48 \mathrm{~h}$, respectively. After the incubation period, colonies were counted to calculate the colony-forming units per milliliter $(\mathrm{CFU} / \mathrm{mL})$. The results were analyzed statistically by analysis of variance (ANOVA) with a $5 \%$ significance level.

\section{Results}

Firstly, the results from this experiment were calculated as percent reduction in CFU/mL (Fig. 1). There was a reduction of $\mathrm{CFU} / \mathrm{mL}$ for C. albicans (33.92\%) and B. atrophaeus 
Table 1 Experimental conditions of groups subjected to PDT with the pre-irradiation time, irradiation time, photosensitizer, and light source

\begin{tabular}{llll}
\hline Irradiation & & & \multicolumn{2}{l}{ Experimental groups } \\
\hline Pre-irradiation (with shaking) $5 \mathrm{~min}$ & Irradiation 3 min & & \\
\hline $\mathrm{X}$ & $\mathrm{X}$ & $\mathrm{P}+\mathrm{L}+$ & Heterotypic biofilm $+100 \mu \mathrm{L}$ rose bengal $+\mathrm{LED}$ \\
$\mathrm{X}$ & & $\mathrm{P}+\mathrm{L}-$ & Heterotypic biofilm $+100 \mu \mathrm{L}$ rose bengal \\
& $\mathrm{X}$ & $\mathrm{P}-\mathrm{L}+$ & Heterotypic biofilm $+100 \mu \mathrm{L}$ solution NaCl $0.9 \%+\mathrm{LED}$ \\
Control Group & & $\mathrm{P}-\mathrm{L}-$ & Heterotypic biofilm $+100 \mu \mathrm{L}$ solution NaCl $0.9 \%$ \\
\hline
\end{tabular}

$P+L+$ photosensitizer and light, $P-L-$ control group, $P-L+$ photosensitizer, $P+L-$ light

(29.31\%) when $\mathrm{P}+\mathrm{L}+$ groups were compared to the control groups $(\mathrm{P}-\mathrm{L}-)$. The biofilms treated with rose bengal $(\mathrm{P}+\mathrm{L}-)$ and laser $(\mathrm{P}-\mathrm{L}+)$ alone demonstrated a number of $\mathrm{CFU} / \mathrm{mL}$ more similar to the control group.

For statistical analysis, the data of $\mathrm{CFU} / \mathrm{mL}$ were converted to logarithmic form $\left(\log _{10}\right)$ and presented in Fig. 2. In this figure, it can be observed that $B$. atrophaeus showed a higher number of $\mathrm{CFU} / \mathrm{mL}$ than $C$. albicans within heterotypic biofilms. For each microorganism, the $\mathrm{P}-\mathrm{L}-, \mathrm{P}+\mathrm{L}+, \mathrm{P}+\mathrm{L}-$, and $\mathrm{P}-\mathrm{L}+$ groups were compared by ANOVA test and statistically significant differences were not found among the groups.

\section{Discussion}

The susceptibility of bacterial and fungal species to the lethal photodynamic effects of various photosensitizing triggers has led to assorted studies seeking to better understand the mechanism of action of antimicrobial photodynamic therapy [16]. Most microorganisms, both in the environment and during the course of infections, form biofilms [17, 18]. The conditions selected for PDT application in this study, including the type and concentration of photosensitizer, light source, and preirradiation time, beyond the described methodology were based on the photoreduction results described in the literature [19].

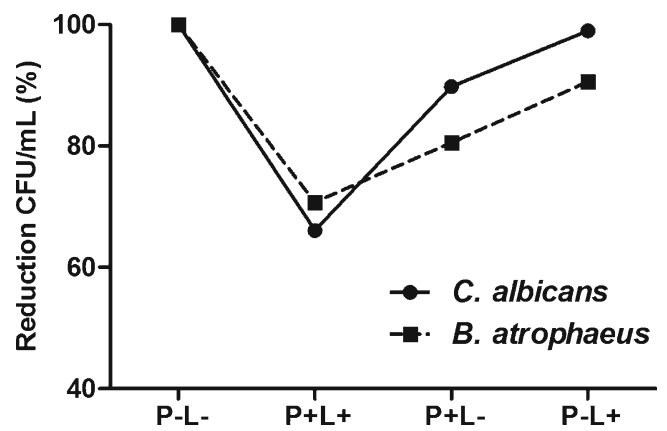

Fig. 1 Percent reduction in CFU/mL of Candida albicans and Bacillus atrophaeus. $P-L^{-}$control group, $P+L+$ photosensitizer and light, $P+L^{-}$ light, $P-L+$ photosensitizer
In general, there are two basic mechanisms associated with photodynamic inactivation proposed to explain the lethal damage caused by PDT to microorganisms: changes in DNA and in the cytoplasmic membrane, allowing extravasation of the cellular contents or the inactivation of membrane transport systems and enzymes [20]. The photodynamic treatment also influences the biofilm structure, causing decreased layer thickness and biomass loss [21].

Regarding the fungal cell wall, there is a relatively thick layer of chitin and beta-glucan that produces a permeability barrier intermediate between Gram-positive and Gramnegative bacteria $[22,23]$. The photodynamic mechanism damages fungal cells when reactive oxygen species penetrate the cell walls and membranes, thus allowing displacement of the photosensitizer into the cell. Then, oxidizing species generated by the excitation of light induce the photodestruction of internal cellular organelles, leading to cell death. Thus, the singlet oxygen generated by the excitation of the photosensitizer is a non-specific oxidizing agent against which there is no cellular defense [18, 24]. Antioxidant enzymes such as catalase and peroxidase protect against some reactive oxygen species but not against singlet oxygen, which inactivates some antioxidant enzymes such as catalase [18].

It has been suggested that the combination of the LED and rose bengal exerts a photodynamic effect on $C$. albicans biofilm. Costa et al. [25] used rose bengal and blue light LED for the photodynamic inactivation of planktonic cultures and

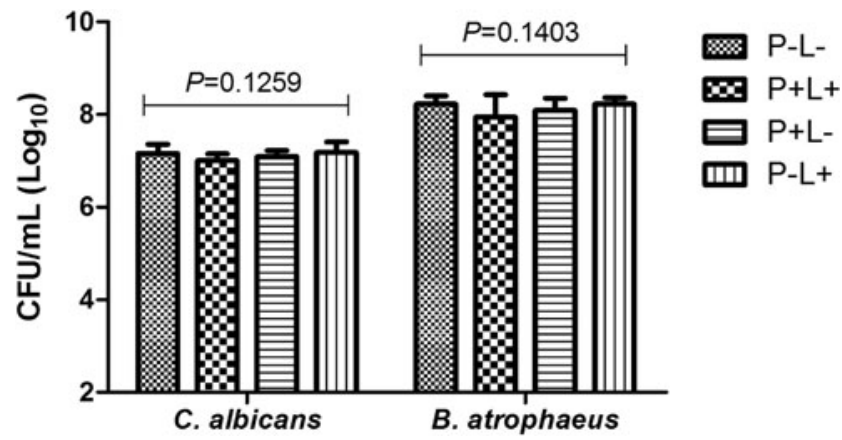

Fig. 2 Mean CFU/mL $\left(\log _{10}\right)$ and standard deviations of Candida albicans and Bacillus atrophaeus for the following groups: $P-L^{-}$ control group, $P+L+$ photosensitizer and light, $P+L^{-}$light, $P-L^{+}$ photosensitizer (ANOVA, $p<0.05$ ) 
biofilms of $C$. albicans and observed a reduction of 1.97 and $0.12 \log _{10}$, respectively. Freire et al. [19] compared the effects of rose bengal and eosin Y photosensitizers in PDT using a green light LED in planktonic cells and the biofilm of C. albicans. The concentrations of the photosensitizers used varied from 0.78 to $400 \mu \mathrm{M}$ for planktonic cultures and $200 \mu \mathrm{M}$ for biofilms. In the biofilms, rose bengal and eosin Y showed microbial reductions of 0.22 and 0.45 , respectively. The result obtained by Costa et al. [25] showed a lower reduction of biofilm formed by $C$. albicans compared to the work performed by Freire et al. [19], suggesting that the concentration of the photosensitizer directly influences the action of photodynamic therapy.

The exposure time of the photosensitizer during preirradiation can also contribute to its access to different locations in the cell. Ito [26] and Usacheva et al. [27] showed that the inactivation mechanism of a cell depends mainly on the time of pre-irradiation to which the photosensitizer is subjected. The difference in the effectiveness of the photosensitizer due to exposure time in the pre-irradiation period may indicate the presence of cellular diffusion barriers that prevent the photosensitizer from reaching an optimal location inside the bacterial cell $[27,28]$.

Therefore, based on the experimental conditions carried out in this study, there was a slight reduction of C. albicans microbial biofilms (33.92\%) and statistically significant difference between the $\mathrm{P}+\mathrm{L}+$ and $\mathrm{P}-\mathrm{L}-$ groups was not observed. The low susceptibility presented by $C$. albicans biofilm can be explained by the structural differences between bacteria and yeast biofilm or the limited penetration of light into the thick biofilms formed by Candida [29]. The non-significant reduction may also be related to the set of factors necessary to establish an appropriate relationship for an effective photodynamic effect: microorganism, photosensitizer (concentration and location in the target cell), type of light source, and preirradiation period.

Rossetti and colleagues [30] studied the effects of antimicrobial photodynamic therapy using toluidine blue as a photosensitizing agent in the production of reactive oxygen species, cell damage, and the ability of $C$. albicans to form biofilms. The authors found a significant decrease in cell growth and increased production of reactive oxygen species and cell permeability after treatment application, with the results dependent on and proportional to the concentration of the photosensitizer and the incubation time $(1,2$, and $3 \mathrm{~h})$ after PDT. After $3 \mathrm{~h}$ of incubation, the authors obtained better microbial reduction: $82 \%$.

Regarding the effect of photodynamic therapy in B. atrophaeus, the results of this study showed a decrease of only $29.31 \%$ in the CFU/mL count, but statistically significant difference was not found between PDT and control groups. The ability of Bacillus spp. cells to differentiate into subtypes with specialized attributes in response to different environmental cues $[31,32]$ suggested that this response to adverse environmental conditions occurs by inducing the expression of adaptive genes. Stochasticity allows bacteria to deploy specialized cells in anticipation of possible adverse changes in the environment [32, 33].

Bacteria in biofilms are less accessible to antibiotics due to protection within the polymer matrix and bacterial adhesion to the surface [34]. Susceptibility testing evaluation studies have been performed, in vitro, in biofilm models and demonstrated significant survival of microorganisms after treatment with antibiotics [35]. Photosensitizer absorption into the matrix is prevented in the same way as antibiotic absorption [21]. Ergaieg and Seux [36] suggested that there are three basic types of photosensitizers: ones that bind tightly to the microorganism and thus penetrate the cell, ones that bind weakly, and ones that do not contact the cell. Thus, there can be variations in the absorption of the photosensitizer by microorganisms.

Studies have demonstrated the successful use of PDT on viruses, Gram-positive, Gram-negative and drug-resistant bacteria, and fungi and yeasts $[37,38]$. Rose bengal is the most common photosensitizing agent used in PDT on these microorganisms [25, 39-41]. Brovko et al. [42] evaluated the application of photodynamic therapy with malachite green and rose bengal at concentrations of 5 to $500 \mu \mathrm{g} / \mathrm{mL}$ in the sanitizing methods of the food industry under the action of white light. Using planktonic cultures of Gram-positive (Bacillus spp. and Listeria monocytogenes) and Gramnegative bacteria (Escherichia coli and Salmonella typhimurium) and fungi (Saccharomyces cerevisiae), it was found that malachite green and rose bengal eliminated Gram-positive bacteria but were not effective against Gramnegative bacteria or fungi. For Bacillus spp., reductions were obtained with malachite green at a concentration of $500 \mu \mathrm{g} /$ $\mathrm{mL}$ and rose bengal at all concentrations. This result suggests the intrinsic relationship between photosensitizer concentration and photodynamic therapy effect.

Thus, the photosensitive inactivation of microorganisms is a complex phenomenon and dependent on various parameters, including the probability of photosensitizer absorption in the cell outer membrane, concentration and location in the target cell [43], microbial species, type of photosensitizer, type of light source, and pre-irradiation time [23].

\section{Conclusions}

The development of mechanisms to promote the inactivation or death of microorganisms, as studied in this experiment, contributes notably to scientific knowledge because $B$. atrophaeus is considered a classic non-pathogenic $B$. anthracis substitute that is, in certain cases, more resistant; and $C$. albicans is an opportunistic pathogen causing many severe and recurrent infections, including fatal invasive 
infections in immunodeficient patients. Thus, photodynamic therapy may be applied as an alternative or adjuvant treatment, acting against various diseases and microorganisms without developing resistance, which is an important and difficult problem that is becoming a key factor in the development of new research. Although the results of this study did not demonstrate significant microbial reduction, they raise the possibility of new experiments important for a wide variety of practical purposes, including the development of practices, strategies, and new formulations with different concentrations, photosensitizers, and light sources for more effective photodynamic action.

Acknowledgments The authors are grateful to FAPESP (Fundação de Amparo à Pesquisa do Estado de São Paulo) for the scholarship provided (Process 2013/22808-0).

\section{Compliance with ethical standards}

Conflict of interest The authors declare that they have no competing interests.

\section{References}

1. Vera DM, Haynes MH, Ball AR, Dai T, Astrakas C, Kelso MJ et al (2012) Strategies to potentiate antimicrobial photoinactivation by overcoming resistant phenotypes. Photochem Photobiol 88:499511. doi:10.1111/j.1751-1097.2012.01087.x

2. Wainwright M (2009) Photoantimicrobials - so what's stopping us? Photodiagnosis Photodyn Ther 6(3-4):167-169. doi:10.1016/ j.pdpdt.2009.10.007

3. Greenberg DL, Busch JD, Keim P, Wagner DM (2010) Identifying experimental surrogates for Bacillus anthracis spores: a review. Investig Genet 1:4. doi:10.1186/2041-2223-1-4

4. Sella SR, Vandenberghe LP, Soccol CR (2014) Life cycle and spore resistance of spore-forming Bacillus atrophaeus. Microbiol Res 169:931-939. doi:10.1016/j.micres.2014.05.001

5. Cutting SM (2011) Bacillus probiotics. Food Microbiol 28:214 220. doi:10.1016/j.fm.2010.03.007

6. Ganguly S, Mitchell AP (2011) Mucosal biofilms of Candida albicans. Curr Opin Microbiol 14:380-385. doi:10.1016/j.mib. 2011.06.001

7. Kim J, Sudbery P (2011) Candida albicans, a major human fungal pathogen. J Microbial 49:171-177. doi:10.1007/s12275-011-10647

8. ten Cate JM, Klis FM, Pereira-Cenci T, Crielaard W, de Groot PW (2009) Molecular and cellular mechanisms that lead to Candida biofilm formation. J Dent Res 88:105-115. doi:10.1177/ 0022034508329273

9. Vilela SF, Junqueira JC, Barbosa JO, Majewski M, Munin E, Jorge AO (2012) Photodynamic inactivation of Staphylococcus aureus and Escherichia coli biofilms by malachite green and phenothiazine dyes: an in vitro study. Arch Oral Biol 57:704-710. doi:10.1016/j. archoralbio.2011.12.002

10. Williams P (2007) Quorum sensing, communication and crosskingdom signalling in the bacterial world. Microbiology 153(Pt 12):3923-3938. doi:10.1099/mic.0.2007/012856-0
11. Martin R, Wächtle B, Schaller M, Wilson D, Hube B (2011) Hostpathogen interactions and virulence-associated genes during Candida albicans oral infections. Int J Med Microbio 301:417422. doi:10.1016/j.ijmm.2011.04.009

12. Hogan DA, Vik A, Kolter R (2004) A Pseudomonas aeruginosa quorum-sensing molecule influences Candida albicans morphology. Mol Microbiol 54:1212-1223. doi:10.1111/j.1365-2958.2004. 04349.x

13. Peleg AY, Hogan DA, Mylonakis E (2010) Medically important bacterial-fungal interactions. Nat Rev Microbiol 8:340-349. doi: $10.1038 /$ nrmicro2313

14. Seneviratne CJ, Silva WJ, Jin LJ, Samaranayake YH, Samaranayake LP (2009) Architectural analysis, viability assessment and growth kinetics of Candida albicans and Candida glabrata biofilms. Arch Oral Biol 54:1052-1060. doi:10.1016/j. archoralbio.2009.08.002

15. Bridier A, Sanchez-Vizuete Mdel P, Le Coq D, Aymerich S, Meylheuc T, Maillard JY et al (2012) Biofilms of a Bacillus subtilis hospital isolate protect Staphylococcus aureus from biocide action. PLoS One 7:e44506. doi:10.1371/journal.pone.0044506

16. Mang TS, Mikulski L, Hall RE (2010) Photodynamic inactivation of normal and antifungal resistant Candida species. Photodiagnosis Photodyn Ther 7:98-105. doi:10.1016/j.pdpdt.2010.03.001

17. Douglas LJ (2003) Candida biofilms and their role in infection. Trends Microbiol 11:30-36. doi:10.1016/S0966-842X(02)00002-1

18. Gonzales F, Maisch T (2012) Photodynamic inactivation for controlling Candida albicans infections. Fungal Biol 116:1-10. doi:10. 1016/j.funbio.2011.10.001

19. Freire F, Costa AC, Pereira CA, Beltrame Junior M, Junqueira JC, Jorge AO (2014) Comparison of the effect of rose bengal- and eosin Y-mediated photodynamic inactivation on planktonic cells and biofilms of Candida albicans. Lasers Med Sci 29:949-955. doi: 10.1007/s10103-013-1435-x

20. Hamblin MR, Hasan T (2004) Photodynamic therapy: a new antimicrobial approach to infectious disease? Photochem Photobiol Sci 3:436-450. doi:10.1039/B311900A

21. Malik R, Manocha A, Suresh DK (2010) Photodynamic therapy—a strategic review. Indian J Dent Res 21:285-291. doi:10.4103/09709290.66659

22. Dai T, Huang YY, Hamblin MR (2009) Photodynamic therapy for localized infections - state of the art. Photodiagnosis Photodyn Ther 6(3-4):170-188. doi:10.1016/j.pdpdt.2009.10.008

23. Silva MP, Junqueira JC, Jorge AO (2014) The effects of photodynamic therapy in oral biofilms. In: Rumbaugh KP, Ahmad I (eds) Antibiofilm agents: from diagnosis to treatment and prevention. Springer, Berlin Heidelberg, Berlin, pp 449-468. doi:10.1007/ 978-3-642-53833-9_20

24. Donnelly RF, McCarron PA, Tunney MM (2008) Antifungal photodynamic therapy. Microbiol Res 163:1-12. doi:10.1016/j.micres. 2007.08.001

25. Costa AC, Rasteiro VM, Pereira CA, Rossoni RD, Junqueira JC, Jorge AO (2012) The effects of rose bengal- and erythrosinemediated photodynamic therapy on Candida albicans. Mycoses 55:56-63. doi:10.1111/j.1439-0507.2011.02042.x

26. Ito T (1983) Photodynamic agents as tools for cell biology. In: Smith KC (ed) Photochemical and photobiological reviews. Springer US, New York, pp 141-186. doi:10.1007/978-1-46844505-3_3

27. Usacheva MN, Teichert MC, Biel MA (2001) Comparison of the methylene blue and toluidine blue photobactericidal efficacy against gram-positive and gram-negative microorganisms. Lasers Surg Med 29:165-173. doi:10.1002/1sm.1105

28. Wagner SJ, Skripchenko A, Robinette D, Foley JW, Cincotta L (1998) Factors affecting virus photoinactivation by a series of phenothiazine dyes. Photochem Photobiol 67:343-349. doi:10.1111/j. 1751-1097.1998.tb05208.x 
29. Dougherty TJ, Gomer CJ, Henderson BW, Jori G, Kessel D, Korbelik M et al (1998) Photodynamic therapy. J Natl Cancer Inst 90:889-905. doi:10.1093/jnci/90.12.889

30. Rosseti IB, Chagas LR, Costa MS (2014) Photodynamic antimicrobial chemotherapy (PACT) inhibits biofilm formation by Candida albicans, increasing both ROS production and membrane permeability. Lasers Med Sci 29:1059-1064. doi:10.1007/s10103-0131473-4

31. López D, Kolter R (2010) Extracellular signals that define distinct and coexisting cell fates in Bacillus subtilis. FEMS Microbiol Rev 34:134-149. doi:10.1111/j.1574-6976.2009.00199.x

32. Sella SR, Vandenberghe LP, Soccol CR (2014) Bacillus atrophaeus: main characteristics and biotechnological applications-a review. Crit Rev Biotechnol 25:1-13. doi:10.3109/ 07388551.2014 .922915

33. Lewis K (2007) Persister cells, dormancy and infectious disease. Nat Rev Microbiol 5:48-56. doi:10.1038/nrmicro1557

34. Vitkov L, Hannig M, Krautgartner WD, Fuchs K (2002) Bacterial adhesion to sulcular epithelium in periodontitis. FEMS Microbiol Lett 211:239-246. doi:10.1111/j.1574-6968.2002.tb11231.x

35. Biel MA (2010) Photodynamic therapy of bacterial and fungal biofilm infections. Methods Mol Biol 635:175-194. doi:10.1007/9781-60761-697-9 13

36. Ergaieg K, Seux R (2009) A comparative study of the photoinactivation of bacteria by meso-substituted cationic porphyrin, rose bengal and methylene blue. Desalination 246(13):353-362. doi:10.1016/j.desal.2008.03.060

37. Santus R, Grellier P, Schrével J, Mazière JC, Stoltz JF (1998) Photodecontamination of blood components: advantages and drawbacks. Clin Hemorheol Microcirc 18:299-308

38. Friedberg JS, Skema C, Baum ED, Burdick J, Vinogradov SA, Wilson DF et al (2001) In vitro effects of photodynamic therapy on Aspergillus fumigatus. J Antimicrob Chemother 48:105-107. doi:10.1093/jac/48.1.105

39. Lazarova G, Tashiro H (1995) Protective effect of amphotericin B against lethal photodynamic treatment in yeast. Microbios 82:187196

40. Lazarova G (1993) Effect of glutathione on rose bengal photosensitized yeast damage. Microbios 75:39-43

41. Demidova TN, Hamblin MR (2005) Effect of cell-photosensitizer binding and cell density on microbial photoinactivation. Antimicrob Agents Chemother 49:2329-2335. doi:10.1128/AAC. 49.6.2329-2335.2005

42. Brovko LY, Meyer A, Tiwana AS, Chen W, Liu H, Filipe CD et al (2009) Photodynamic treatment: a novel method for sanitation of food handling and food processing surfaces. J Food Prot 72:1020 1024

43. Canete M, Villanueva A, Juarranz A (1993) Uptake and photoeffectiveness of two thiazines in HeLa cells. Anticancer Drug Des 8:471-477 